EISSN:2706-7920 ISSN: 2077-4435

DOI: $10.36632 / \mathrm{csi} / 2021.10 .1 .1$

Journal homepage: www.curresweb.com

Pages: $1-7$

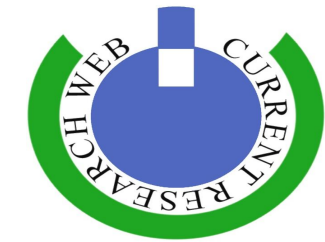

\title{
A Cast Titanium Obturator Framework in Rehabilitation of Acquired Maxillary Defects
}

\section{${ }^{1}$ Emad Ahmed Awad, ${ }^{2}$ Magdy Mostafa M. Mostafa, ${ }^{3}$ Abdel Salam Kh. Ezzat, ${ }^{4}$ Khaled K. El-Din Amin and ${ }^{5}$ Hatem K. El-Din Amin.}

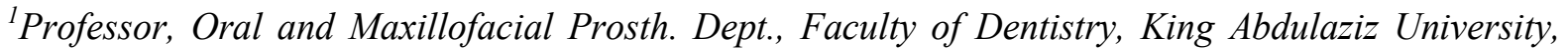
Jeddah, Saudi Arabia. and Prosth. Dept., Faculty of Dentistry, Alexandria University, Egypt.

${ }^{2}$ Professor, Oral and Maxillofacial Prosth. Dept., Faculty of Dentistry, King Abdulaziz University, Jeddah, Saudi Arabia.

${ }^{3}$ Professor, Oral and Maxillofacial Prosth. Dept., Faculty of Dentistry, King Abdulaziz University, Jeddah, Saudi Arabia and Prosth. Dept., Faculty of Dentistry, Alexandria University, Egypt.

${ }^{4}$ Associate Professor, Oral and Maxillofacial Prosth. Dept., Faculty of Dentistry, King Abdulaziz University, Jeddah, Saudi Arabia and Prosth. Dept., Faculty of Dentistry, El Nahda University, Egypt.

${ }^{5}$ Professor, Oral and Maxillofacial Prosth. Dept., Faculty of Dentistry, King Abdulaziz University, Jeddah, Saudi Arabia. and Prosth. Dept., Faculty of Dentistry, Cairo University, Egypt.

Received: 10 November 2020 Accepted: 25 December 2020 Published: 10 January 2021

\begin{abstract}
This study was carried out to study the effect of using a cast titanium framework that retain maxillary obturators on the periodontal condition of remaining teeth. Twelve patients with post-surgical maxillary defects were selected, and according to the type of metal framework of the intended maxillary obturator, the patients were categorized into two groups, six patients each. In group 1, patients received obturators, the metal framework of which was made of cobalt chromium alloy, while in group 2, patients received titanium metal framework obturators. Clinical as well as radiographic evaluations were carried out as evaluation tools. The results obtained from this study revealed insignificant effect of using cast titanium obturator framework on the periodontal condition of the remaining condition when compared to the conventional cast cobalt-chromium obturator framework.
\end{abstract}

Keywords: a cast titanium framework, remaining teeth, obturators,

\section{Introduction}

A total or subtotal resection of the maxilla to eradicate malignant or locally invasive lesions often results in loss of important vital physiologic functions of the oral cavity. The internal as well as the facial alterations can result in significant psychological problems to the patient. After such resections, preservation of the remaining dentition is of particular importance for the retention, stability, and support of the obturator prosthesis (Schwartzman et al., 1985 and George et al., 2015).

The loss of support at the defect side causes an obturator prosthesis to move significantly during function which delivers increased pressure, torque, and lever action on the supporting hard and soft tissues (Aramany, 1978).

The metal framework design must anticipate and accommodate for the movements of the obturator during function without exerting undue stresses on the remaining teeth. Forces are transmitted to abutment teeth by rests, guide planes, and retainers. Optimum framework designs should, therefore, be based on sound research data and clinical experience aimed at preserving the 
health of the abutment teeth and their supporting structures (Martin and King, 1984 and Reitemeier et al., 2016).

A variety of methods to distribute the potentially damaging force during function have been described (Goodkind, 1973 and Krol, 1973). Many authors (Aramany, 1978, Krol, 1973, Desjardins, 1978 and Patil and Nimbalkar-Patil, 2017) discussed obturator framework design for acquired maxillary defects. However, the metal used for framework construction was not a subject of interest. For more than half a century, the favored metal for the construction of an obturator framework has been the Co-Cr alloy. Recent developments in titanium casting technology nowadays provide an opportunity to utilize this metal for the construction of denture frameworks (Bridgemen et al., 1997 and Bolan et al., 2014). Titanium has become a material of great interest in prosthodontics in recent years. The evolution of titanium applications to the medical and dental fields has dramatically increased in the past few years because of its excellent biocompatibility, corrosion resistance, and desirable physical and mechanical properties (Baltag et al., 2002 and Ferro et al., 2017) A considerable amount of research has been directed towards dental casting of titanium and titanium alloys (Cecconi et al, 2002 and Jang et al., 2001) however, the metal is still a difficult material to cast .High fusing temperature and chemical activity preclude the use of the conventional dental casting procedure and require an improved casting system based on an electric arc design for melting in an argon atmosphere to reduce oxidation of the metal (Wakabayashi and Ai, 1997). Several studies (Bridgemen et al., 1997, Salah, 1999 and El-Rafa et al., 2001) investigated and compared the properties of various cast alloy materials regarding their uses in conventional RPD. However, there is insufficient data regarding the comparison of the use of cobalt-chromium and titanium alloys as metal frameworks for obturator prostheses.

\section{Materials and Methods}

Twelve patients who had undergone maxillary resection categorized as class II based on Aramany's classification (Aramany, 1978) were selected for this study. All patients had completely healed surgical defects (surgeries had been performed since over six months). Almost, the whole natural teeth were preserved on the defect and non-defect side (Fig. 1). Patients were divided into two groups, six patients each. In group 1 patients received obturators, the metal framework of which was made of cobalt chromium alloy (Wironit. BEGO Bremer Gold Schlagerei), while group 2 patients received titanium metal framework obturators (Ti-6 A1-4 V (Bio-Ti, Jeneric/Pentron, Wallingford).

Similar metal framework designs were constructed for all patients. The anterior abutment adjacent to the defect was engaged by a combination clasp (wrought wire retentive arm). On the non defect side, cast circumferential clasps were used. A full palatal coverage connector was employed in all designs. A hollow bulb obturator part was constructed of heat curing acrylic resin (Fig 2). Patients were evaluated clinically and radiographically throughout the study.

\subsection{Clinical Evaluation}

Assessment of the periodontal parameters of all natural teeth abutments including; plaque index (Silness and Loe, 1964), gingival index (Loe and Silness, 1963) probing depth (Glavind and Loe, 1967) attachment loss (Glavind and Loe, 1967) and mobility (Mckinney and Koth, 1982) was performed in all patients immediately after the prosthesis insertion and then every 3 months up to one year.

\subsection{Radiographic Evaluation}

Radiographic assessment of the vertical bone loss was carried out through a standardized periapical radiographic survey with a superimposed grid. The marginal bone height around the teeth was measured immediately after prosthesis insertion, six and twelve months later. 


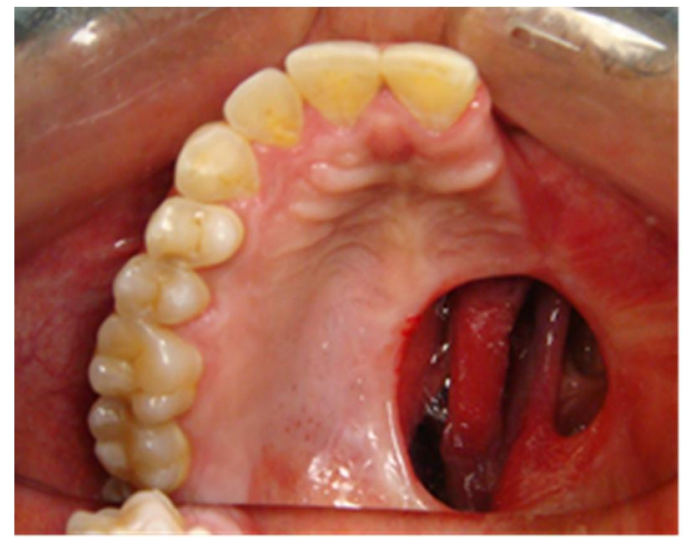

Fig. 1: Patient who had undergone right maxillary resection

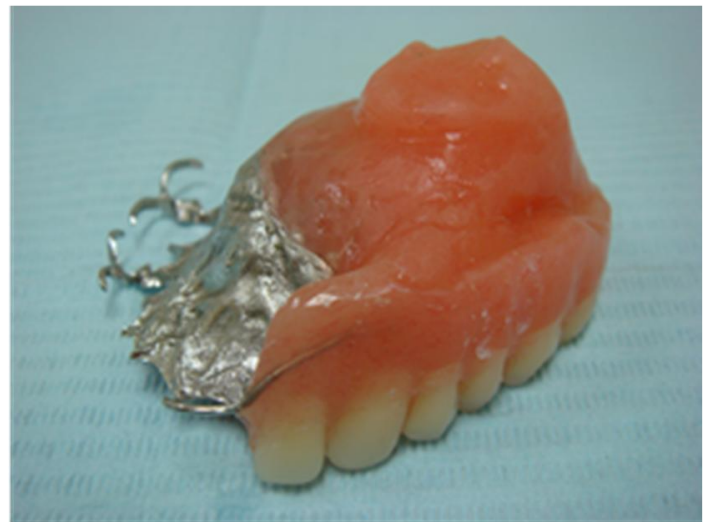

Fig 2: Cast titanium-based obturator

\section{Results and Discussion}

\subsection{Clinical Evaluation}

The data collected from the estimation of the periodontal parameters of all natural teeth was tabulated and statistically analyzed within and in between the two groups under study according the method originally described by Mann-Whitney and Wilcoxon (Spss/Win, 1993) to test the clinical significance of these non-parametric data.

\subsection{Plaque Index}

The mean plaque index score for group I was not significantly different from that of group II $(p=0.2856)(p>0.05)$ at the initial observation stage. In both groups there were a slight increase in the plaque score at the 3 and 6 months interval, however with no statistical difference between the two groups. A noticeable reduction in the plaque score was observed at the 9 months interval but not clinically significant from the initial stage in both groups. Eventually, after one year observation stage, a significant decrease in plaque index score from the base line values were detected in both groups (Table 1). However, with insignificant difference between groups $(\mathrm{p}=0.1453)(\mathrm{p}>0.05)$.

Table 1: Wilcoxon- Matched pairs signed ranks test of plaque index with baseline (at time of prosthesis insertion)

\begin{tabular}{ccccc}
\hline Group & 3 Months & 6 Months & 9 Months & 12 Months \\
\hline Group I & 0.342 & 0.502 & 0.299 & $0.0398^{*}$ \\
Group II & 0.322 & 0.067 & 0.1332 & $0.0245^{*}$ \\
\hline
\end{tabular}

${ }^{*} \mathrm{p}<0.05$ (clinically significant)

\subsection{Gingival Index}

No significant difference in the mean gingival index score between the two groups at the initial observation stage $(\mathrm{p}=0.7860)(\mathrm{p}>0.05)$. At the subsequent stages of observation, there was a gradual 
diminish in the mean recorded scores for both groups up to the final observation stage, However, no statistical significance was noticed neither between the groups nor from the base line values. (Table 2)

Table 2: Wilcoxon- Matched pairs signed ranks test of gingival index with baseline (at time of prosthesis insertion)

\begin{tabular}{ccccc}
\hline Group & 3 Months & 6 Months & 9 Months & 12 Months \\
\hline Group I & 0.224 & 0.441 & 0.332 & 0.451 \\
Group II & 0.452 & 0.775 & 0.775 & 0.666 \\
\hline
\end{tabular}

$\mathrm{P}>0.05$ (clinically insignificant)

\subsection{Probing Depth}

The mean probing index score for both groups were not significantly different from each other from base line up to the subsequent evaluation periods of 6,9 and 12 months $(\mathrm{p}>0.05)$. There was a gradual reduction in the mean probing depth in group 1 from the 6 months evaluation stage to the following 9 and 12 months. However, no statistical significance was noticed from the base line values. ( $>0.05$ ). In group 2 there was a mild change in the values during all observation sessions with eventual insignificant increase in the probing depth from the base line. $(\mathrm{p}>0.05)$ (Table 3$)$.

Table 3: Wilcoxon- Matched pairs signed ranks test of probing depth with baseline (at time of prosthesis insertion)

\begin{tabular}{ccccc}
\hline Group & 3 Months & 6 Months & 9 Months & 12 Months \\
\hline Group I & 0.098 & 0.0991 & 0.214 & 0.115 \\
Group II & 0.132 & 0.0879 & 0.0771 & 0.0980 \\
\hline
\end{tabular}

$\mathrm{P}>0.05$ (clinically insignificant)

\subsection{Epithelial Attachment Loss}

No significant difference in the mean attachment loss was noticed between both groups at the initial observation stage $(p=0.1430)(p>0.05)$. This was also noticed at the $3,6,9$ and 12 months interval $(\mathrm{p}>0.05)$. No significant difference from base line was found in both groups along the whole observation period. (Table 4).

Table 4: Wilcoxon- Matched pairs signed ranks test of epithelial attachment loss with baseline (at time of prosthesis insertion)

\begin{tabular}{ccccc}
\hline Group & 3 Months & 6 Months & 9 Months & 12 Months \\
\hline Group I & 0.143 & 0.0881 & 0.114 & 0.0991 \\
Group II & 0.445 & 0.0554 & 0.0882 & 0.1537 \\
\hline
\end{tabular}

$\mathrm{P}>0.05$ (clinically insignificant)

\subsection{Mobility}

The mean mobility score was not changed along the whole observation stage neither between the groups nor from the initial observation stage. The mean mobility was score for group 10.114 while for group 2 was 0.

\subsection{Radiographic Evaluation}

The mean annual bone loss at the proximal surface of natural teeth in group 1 was not significantly different from that recorded in group $2(\mathrm{p}=0.155)(\mathrm{p}>0.05)($ Table 5).

Table 5: Mann-Whitney U - Wilcoxon rank sum W test of bone loss by group.

\begin{tabular}{cccc}
\hline Abutment & U & W & 2-Tailed P \\
\hline Natural teeth & 7.86 & 43.0 & 0.155 \\
\hline $\mathrm{P}>0.05$ (clinically insignificant) & & &
\end{tabular}

\section{Discussion}

Many variables must be considered when evaluating the load-induced stresses on the remaining dentition produced by the cantilever action of maxillary obturator prosthesis. One important variable 
is the material construction of the framework. Several studies have investigated the extent and direction of movement during function of a removable partial denture (RPD) fabricated for a radical maxillectomy defect and the effect of the movement on key teeth. Fiebiger et al. (1975) attempted to delineate the movements of abutment teeth in radical maxillectomy defects when three common framework designs were subjected to forces of known direction and magnitude. Schwartzman et al., 1985 tried to photo-elastically compare and evaluate the forces exerted on the supporting structures of abutment teeth by the RPD designs most used in the restoration of a radical maxillectomy defect. However, the limitations of these experimental studies, the effect of changing the alloy metal and the lack of a clinical evaluation guide, prevented the authors from making any substantive conclusions, and further studies were recommended. Therefore, this study was undertaken to provide additional insight into the effect of load-induced stresses by the metal framework of a maxillary obturator when the material construction of the obturator framework is changed.

Several attempts have been made to reduce the cantilever effect and prevent the rotation of the obturator out of the maxillectomy cavity. These attempts include; the use of guiding planes on the remaining teeth parallel with the defect wall, extension of the obturator prosthesis onto the pharyngeal surface of the soft palate and extending the lateral border of the prosthesis as high into the defect as possible to minimize the vertical displacement under load (Aramany, 1978). Some favored the use of bone-anchored implants into the surgical cavity (Gary et al., 1992), however the implant option poses particular surgical and prosthodontic challenges, and may well be met with resistance by patients who are understandably, reluctant to further surgical procedures. The use of base metal alloys in prosthdontics is an unquestionable necessity, and the use of cobalt-chromium alloys has permitted high quality treatment for a large number of patients of limited financial means. However, arguments for the use of titanium alloys because of its biocompatibility and different mechanical properties seem to be realistic.

Interest in titanium for dental prostheses increased in the early 1980s (Kononen and Rintanen 1995). There have been a number of studies on the use of titanium (Ti) and Ti alloys for removable prosthodontics (Bridgemen et al., 1997 and Cecconi et al., 2002). Titanium has a modulus of elasticity that is lower than that of cobalt -chromium, which increases its resiliency and makes it more like gold alloys. This property suggests that titanium alloys are more biomechanically acceptable materials for construction of RPD frameworks that support a maxillary obturator than cobaltchromium. A reduction in the magnitude of the leverage induced stresses on the remaining dentition is therefore expected. However, the results of this study based on clinical observations and, radiographic findings failed to find a significant difference between the titanium and $\mathrm{Co}-\mathrm{Cr}$ alloys regarding that aspect.

Assessing the clinical results revealed that the introduction of the obturator prosthesis into the oral cavity at the first 3 months of treatment adversely affected the prevailing ecologic condition in terms of plaque formation and increased gingival inflammation in both groups. However, with maintenance of an acceptable oral hygiene level, a reduction in all scores was found. Analysis of the radiographic material revealed that hardly minor bone changes around natural teeth could be observed in both groups.

The results of this study seem to ignore the suggestion that the titanium long term resiliency could compensate for the leverage-induced stresses and that the effect of the lever force transmitted to the remaining dentition was so destructive to be compensated by changing the type of alloy metal. Another observation is that the titanium casting made with recently developed casting systems still poses a particular problem. It has been reported that mechanical properties of the casting may differ significantly from the parent metal, and the outer 100 to $200 \mu \mathrm{m}$ of the outer surface of the casting exhibited greater hardness and reduced ductility compared with the core material (Doi et al., 1992). To overcome these casting problems, several fabricating systems that embrace the concept of computer assisted design and computer assisted machining (CAD/CAM) have recently been introduced.

It must be clear that finished surfaces of all frameworks exhibited a smooth shiny layer before insertion. However, surface discoloration of the metal or a slight loss of surface luster was obvious in a patient after 3 months of service. It has been stated that titanium has high corrosion resistance in oral fluids because of the early formation of oxide film on the surface but a low antibacterial effect in any. Careful considerations should therefore be given to the maintenance of the patient's oral hygiene and 
cleanliness of titanium prostheses to avoid adsorption of hard and soft deposits which may contain specific oral bacteria. The titanium framework in the study demonstrated horizontal flexibility, but little vertical flexibility. In the mouth, the titanium framework was stable on the remaining teeth. The clasps functioned well because of the good recovery properties of titanium. The patient's comments about the titanium framework's being comfortable, tasteless, and warm can be explained because of the excellent corrosion resistance, and low thermal conductivity of titanium.

During this one-year trial it was observed that most patients found Ti frameworks more comfortable and easier to remove than the Co-Cr RPDs. In addition, although the yield strength of $\mathrm{Ti}$ frameworks is lower than that of Co-Cr frameworks, it was sufficiently high to prevent deformation of clasps and patients did not find noticeable loosening of the dentures.

\section{References}

Aramany, M.A., 1978. Basic principles of obturator design for partially edentulous patients. Part I: classification. J Prosthet Dent., 40:554-57.

Aramany, M.A., 1978. Basic principles of obturator design for partially edentulous patients. Part II: Design principles. J Prosthet Dent., 40:656-62.

Baltag, I., K Watanabe, H. Kusakari and O. Miyakawa, 2002. Internal porosity of cast titanium removable partial dentures: Influence of sprue direction on porosity in circumferential clasps of a clinical framework design. J Prosthet Dent., 88:151-8.

Bolan, M., C. Kosmann, G.V. Teixeira, L.J. Grando, J.N. Seára and L.H. Rau, 2014. The use of oral maxillofacial prosthesis in post-maxillectomy rehabilitation: A case report. OHDM., 13:75-9.

Bridgemen, J.T., M.S. Marker, S.K. Hummel, B.W. Benson and L.L. Pace, 1997. Comparison of titanium and cobalt-chromium removable partial denture clasps. . J Prosthet Dent., 78:187-193.

Cecconi, B.T., R.G. Koeppen, R.D. Phoenix and M.L. Cecconi, 2002. Casting titanium partial denture frameworks: a radiographic evaluation. J Prosthet Dent., 87:277-8049.

Desjardins, R.P., 1978. Obturator prosthesis design for acquired maxillary defects. J Prosthet Dent., 39:424-32.

Doi, H., T. Yoneyma and M. Kotake, 1992. Influence of surface reaction layer on mechanical properties of titanium castings. J Dent Mater., 11:17-22.

El-Rafa, I.Z., M. Saber and M.A. Aly, 2001. Biological aspects of cobalt-chromium complete denture bases. Egypt Dent J., 47:941-49.

Ferro, K.J., C.F. Driscoll, M.A. Freilich, A.D. Guckes, K.L. Knoernschild and T.J. McGarry, 2017. The glossary of prosthodontic terms: Ninth edition. J Prosthet Dent., 117(5S):e62.

Fiebiger, G.E., A.O. Rahan, D.O. Lundquist and P.K., 1975. Morse Movement of abutments by removable partial denture frameworks with hemimaxillectomy obturator. J Prosthet Dent., 34:555-60.

Gary, J.J., M. Donovan, F.T. Gardener and J.E. Faulk, 1992. Rehabilitation with calvarial bone grafts and osseointegrated implants after partial maxillary resection. J Prosthet Dent., 67:743-46.

George, K., A.J Barber, P.H.R Wilson, 2015. Cast Titanium for Obturator Framework Construction in Maxillofacial Prosthodontics. Eur J Prosthodont Restor Dent., 23(4):213-8.

Glavind, L., H. Loe, 1967. Errors in the clinical assessment of periodontal destruction. J periodontal Res., 2:180-188.

Goodkind, R., 1973. The effect of removable partial dentures on abutment tooth mobility. A clinical study. J Prosthet Dent., 30:139-45.

Jang, K.S., S.J. Youn and Y.S. Kim, 2001. Comparison of castability and surface roughness of commercially pure titanium and cobalt-chromium denture frameworks. J Prosthet Dent., 86:93-8.

Kononen, M. and J. Rintanen, 1995. Titanium framework removable partial denture used for patient allergic to other metals. J Prosthet Dent., 73:4-7.

Krol, A.J., 1973. Clasp design for extension-base removable partial dentures. J Prosthet Dent., 29: $108-16$.

Loe, H. and J. Silness, 1963. Periodontal diseases in pregnancy I. Prevalence and severity. Acta Odontol Scand., 21:533-551. 
Martin, J. and G.E. King, 1984. Framework retention for maxillary obturator prostheses. J Prosthet Dent., 51: 669-72.

Mckinney, J.R., D.L. Koth, 1982. The single-crystal sapphire endosteal dental implant. J Prosthet Dent., 47:69-73.

Patil, P.G. and S. Nimbalkar-Patil, 2017. Lost wax-bolus technique to process closed hollow obturator with uniform wall thickness using single flasking procedure. J Indian Prosthodont Soc., 17: 848.

Reitemeier, B., W. Schaal and A. Wolf, 2016. Walter M. Sealing maxillary titanium obturators with removable flexible caps. J Prosthet Dent., 115: 381-3.

Salah, F., 1999. Monitoring of adherent molecules, pro-inflammatory cytokines and oral bacterial colonization among titanium versus cobalt chromium denture wearers. Ainshams Dent J., II: 32334.

Schwartzman, B., A. Caputo and J. Beumer, 1985. Occlusal forces transfer by removable partial denture designs for a radical maxillectomy. J Prosthet Dent., 54:397-403.

Silness, J. and H. Loe, 1964. Periodontal diseases in pregnancy. Acta Odontol Scand., 1964; 22:121135.

Spss/Win. Statistical package for social sciences under windows. Basic system's user guide release. 6 . O spss Inc., 1993.

Wakabayashi, N. and M. Ai, 1997. A short-term clinical follow-up study of superplastic alloy for major connectors of removable partial dentures. .J Prosthet Dent., 77:583-87. 